\title{
MICROALBUMINURIA AND ITS ASSOCIATION WITH GLYCEMIC CONTROL IN PATIENTS WITH DIABETES MELLITUS TYPE II.
}

1. MBBS, M.Phil (Haematology) Assistant Professor Pathology Indus Medical College Tando Muhammad Khan.

2. MBBS, MD (Medicine)

Assistant Professor Medicine Indus Medical College Tando Muhammad Khan.

3. MBBS, M.Phil (Physiology) Assistant Professor Physiology Isra University Hyderabad.

4. MBBS, M.Phil (Physiology) Assistant Professor Physiology Isra University Hyderabad.

5. MBBS, M.Phil (Anatomy) Assistant Professor Anatomy Isra University Hyderabad.

6. MBBS, M.Phil (Biochemistry) Assistant Professor Biochemistry Isra University Hyderabad.

Correspondence Address:

Dr. Shahzad Ali Jiskani

Department of Pathology

Indus Medical College Tando

Muhammad Khan.

shahzadbaloach289@gmail.com

Article received on:

29/10/2019

Accepted for publication:

$30 / 12 / 2019$
Shahzad Ali Jiskani ${ }^{1}$, Dolat Singh ${ }^{2}$, Kumayl Abbas Meghji ${ }^{3}$, Rizwan Ali Talpur ${ }^{4}$, Jahanzaib Khan ${ }^{5}$, Hina Nazeer Khanzada ${ }^{6}$

ABSTRACT: Diabetes mellitus is chronic condition with defect in regulation of insulin. Microalbuminuria is one of the early appearing markers of overt diabetic nephropathy. Uncontrolled glycemic status has been postulated to be associated with increase urinary albumin levels. Objectives: To find out the association of increased urinary albumin with poor glyemic status of patients with diabetes mellitus type II. Study Design: Cross Sectional study. Setting: Department of Pathology, Indus Medical College Hospital Tando Muhammad Khan. Period: November 2018 to June 2019. Material \& Methods: Patients were divided into two groups: Group I (Poor glycemic control, HbA1c >7\%) and Group II (Good glycemic control, $\mathrm{HbA} 1 \mathrm{c}<7 \%)$. Glycated hemoglobin and microalbuminuria were evaluated in all patients. Data was analyzed using SPSS 21.0. P - value of $<0.05$ was considered as statistically significant. Results: Total of 213 patients were included in the study with male ratio $(56.8 \%)$ slightly higher than females (43.19\%). Mean age of patients was $42.3 \pm 2.1$ years. Mean glycated hemoglobin in Group I and II was $8.12 \pm 0.97 \%$ and $5.98 \pm 0.41 \%$ respectively. In Group I, 57.54\% patients were detected with microalbuminuria as compared to Group II (12.26\%). P value was statistically significant $(<0.001)$. Conclusion: Microalbuminuria was found more frequently in patients with poor glycemic control. Early detection of urinary microalbumin in these patients may decrease the risk of kidney damage and appropriate and adequate management in initial stage.

Key words: $\quad$ Diabetes Mellitus, Diabetic Nephropathy, Glycemic Control, Hyperglycemia, Microalbuminuria.

Article Citation: Jiskani SA, Singh D, Meghji KA, Talpur RA, Khan J, Khanzada HN. Microalbuminuria and its Association with Glycemic Control in Patients with Diabetes Mellitus Type II. Professional Med J 2020; 27(8):1617-1620. DOI: 10.29309/TPMJ/2020.27.08.4305

\section{INTRODUCTION}

Diabetic nephropathy is one of the leading causes of chronic kidney failure. ${ }^{1}$ Diabetes mellitus is a chronic condition of carbohydrate, protein and fat metabolism due to deficiency of insulin and/ or resistance of insulin. Chronic hyperglycemia of diabetes results in various dysregulation of immune system which is related to irreversible and permanent structural and functional changes in the cells of body with long - term damage., ${ }^{2,3}$ Microalbuminuria has been defined as excretion of urinary albumin in 24 - hour urine or short time collection of urine during daytime in the range of $30-300 \mathrm{mg} / 24$ hour $(20-200 \mu \mathrm{g} /$ min). ${ }^{4,5}$ The increased level of albumin in the urine may represent more generalized damage to the vasculature than microvasculature injury alone to the renal parenchyma. Hyperperfusuion to the glomerulus and hypertrophy of the renal calyces occurs in initial phase after onset of diabetes mellitus, which is reflected by increase in glomerular filtration rate (GFR) ${ }^{6-8}$

Screening of microalbumin can be done using quantitative methods including measurement of albumin to creatinine ratios in random sample of urine, 24 - hour collection with creatinine, which allows the simultaneous measurement of creatinine clearance, timed (e.g. 4 hourly) overnight collection of urine for protein, or it can be measured using semi - quantitative reagent dipsticks. $^{9}$

Microalbuminuria is found in more than one third of diabetic patients. Mortality of diabetic patients is increased 40 times with proteinuria. 
It denotes the single most and most sensitive prognostic factor to assess the risk of evident diabetic nephropathy and it reflects the initial stage of progressive diabetic renal disease. ${ }^{10,11}$

The objective of this study was to evaluate the association between poor glycemic control and presence of microalbuminuria in patients with diabetes mellitus type II.

\section{MATERIAL \& METHODS}

This was a cross sectional study carried out in Department of Pathology, Indus Medical College Tando Muhammad Khan from November 2018 to June 2019. Patients included were ages above 30 years and below 55 years, both genders, patients with both controlled and uncontrolled diabetes mellitus type II.

Diabetic patients were divided into two groups: Patients with poor glycemic control (HbA1c $>7 \%$ ) in Group I and with good glycemic control $(\mathrm{HbA} 1 \mathrm{c}<7 \%)$ in Group II. Participants with history of hypertension, kidney disease and persons on medication which function of kidney like ACE inhibitors, ARBs, diuretics and NSAIDs were excluded from the study.

Taking all antiseptic and aseptic precautions, $3 \mathrm{~mL}$ of blood was taken from anterior cubital vein and 24-hours sample of urine was collected in sterilized container for $\mathrm{HbA1c}$ and microalbuminuria detection respectively. HbA1c was measured by cation - exchange resin method using Spectrophotometer. Microalbuminuria was detected by dipstick method in urine.

Data was analyzed using SPSS 21.0. Chi - square test was applied. $\mathrm{P}$ - value of $<0.05$ was found statistically significant.

\section{RESULTS}

Total of 213 patients participated in the study. Males were 121 (56.8\%) and 92 (43.19\%) were female (Figure-1). Group I consisted of 107 (50.23\%) patients and Group II consisted of 106 (49.76\%) patients. Mean age of patients was 42.3 \pm 2.1 years. Mean glycated hemoglobin in Group I was $8.12 \pm 0.97 \%$ and $5.98 \pm 0.41 \%$ in Group II (Table-I). In Group I, 61 (57.54\%) patients were detected with microalbuminuria, while in Group $13(12.26 \%)$ were detected with microalbuminuria (Table-II), with $\mathrm{P}$ value was $<0.001$.

\section{Gender Distribution $(\mathrm{n}=\mathbf{2 1 3})$}

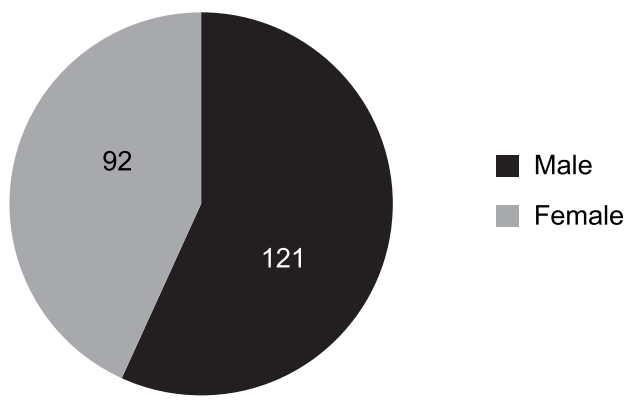

Figure-1. Gender Distribution $(n=213)$.

\section{DISCUSSION}

Diabetes mellitus type II is increasing as a fatal disease, with nephropathy identified as endothelial dysfunction and it usually occurs in generalized manner in patients with diabetes mellitus type II., ${ }^{52}$ There is high prevalence of both micro - and macrovascular complications in diabetic patients including nephropathy etc. ${ }^{13}$

\begin{tabular}{|l|c|c|c|}
\hline \multicolumn{1}{|c|}{ Groups } & Number of Participants (\%) & HbA1c (\%) & P-Value \\
\hline Group I (Uncontrolled DM) & $107(50.23 \%)$ & $8.12 \% \pm 0.97 \%$ & $<0.001$ \\
\hline Group II (Controlled DM) & $106(49.76 \%)$ & $5.98 \pm 0.41 \%$ & \multirow{2}{*}{ Table-I. Comparison of Glycated Hemoglobin in Both Groups (n=213). } \\
\hline
\end{tabular}

\begin{tabular}{|l|c|c|}
\hline \multicolumn{1}{|c|}{ Groups } & Microalbuminuria (N) & P-Value \\
\hline Group I (Uncontrolled DM) & $61(57.54 \%)$ & $<0.001$ \\
\hline Group II (Controlled DM) & $13(12.26 \%)$ & \\
\hline & Table-II. Detection of Microalbuminuria in Both Groups (n=213). \\
\hline
\end{tabular}


In our study, the patients with uncontrolled diabetes mellitus were proven to be more prevalent by the presence of microalbumin in their urine. The $p-$ value was statistically significant as compared in both groups $(<0.001)$. Although patients with controlled glycemic status show less detection of microalbuminuria. A significant correlation was also found in various studies.

Showail et all showed in study that uncontrolled glycemic control was highly associated with microalbuminuria development, having good therapeutic implications. ${ }^{14}$ Efundem et al proved that microalbuminuria is associated with high systolic and diastolic blood pressure, and declining kidney function, suggesting the leading mechanism towards the kidney damage. ${ }^{15}$ Chen et al explained the role of microalbuminria with glycemic control, with his results proving the relationship of high - normal albuminuria and glycemic control on microalbuminuria development among patients with diabetes mellitus type II. ${ }^{16}$ Khalid et al showed in his study and proved the positive correlation between increased frequency of microalbuminuria and glycemic control. ${ }^{17}$ Memon et al showed that by improving the glycemic control of diabetic patients, maintenance of the blood pressure can be ensured; and early diagnosis of the disease may decrease the risk of development and progression of microalbuminuria and finally end stage damage of kidney and mortality. ${ }^{18}$ Habib et al showed that microalbuminuria showed little or no association with age of the patients and highly associated with $\mathrm{HbA1c}$ levels in diabetic patients. ${ }^{19}$ Verma et al showed that impaired control of glucose is related to increased urinary levels of albumin and is proven to be high risk marker of diabetic nephropathy. ${ }^{20}$

Kumar et al showed that high prevalence of microalbuminuria was present among the patients of diabetes mellitus with poor glycemic control. ${ }^{13}$

Similar findings were present in this study with high rate of urinary albumin, 61 (57.54\%) in diabetic patients with poor glycemic control. In our society, various causes of microalbuminuria are found, including race, smoking, heavy poisoning with metals, exercise, connective tissue disorders, use of drugs (e.g. NSAIDs), sickle cell disease, obesity, and family history of hypertension or diabetes mellitus. ${ }^{21,22}$

\section{CONCLUSION}

Microalbuminuria was found frequently in diabetic patients with poor glycemic control. Early detection of urinary microalbumin in these patients may decrease the risk of renal damage and appropriate management at early stage.

\section{Copyright $@ 30$ Dec, 2019.}

\section{REFERENCES}

1. Varghese A, Deepa R, Rema M, Mohan V. Prevalence of microalbuminuria in type 2 diabetes mellitus at a diabetes centre in southern India. Postgr Med J. 2001; 77:399-402.

2. Prakash S, Yadav K. Microalbuminuria in diabetes. Lett Heal Biol Sci. 2017; 2(1):52-60.

3. Macisaac RJ, Ekinci El, Jerums G. Progressive diabetic nephropathy. How useful is microalbuminuria? Kidney Int. 2014; 86(1):50-7.

4. R S, Bin HS, Pajica P, Zeljko M. Microalbuminuria and diabetes mellitus. Diabetol Croat. 2002; 31(4):209-21.

5. Naveen P, Venkatesan R, Ashwath R, Venkidusamy $S$. Effect of glycemic control in incidence of microalbuminuria in type ii diabetes mellitus individuals. Natl J Physiol Pharm Pharmacol. 2014; 4(2):132-4.

6. Mohan MM, V CS. Prevalence and risk factors of microalbuminuria in type 2 diabetes mellitus. Int $\mathrm{J}$ Adv Med. 2015; 2(4):383-6.

7. June LW, Lucia S, Jeong LM, Ho KM, Mincheol S, Heeyoon $C$. The relationship between diabetic retinopathy and diabetic nephropathy in a populationbased study in Korea. IOVS. 2014; 55(10):6547-53.

8. Rodrigues $M$, Dias $C B$. Microalbuminuria in nondiabetic population as marker of nephropathy. J Bras Nefrol. 2016; 38(2):203-8.

9. Al-maskari F, El-sadig M, Obineche E. Prevalence and determinants of microalbuminuria among diabetic patients in the United Arab Emirates. BMC Nephrol. 2008; 9(1):1-8.

10. Ambayiram AV, Kalyani P, Govindarajan PK. Prevalence of microalbuminuria among type II diabetes mellitus patients in urban Chidambaram. Saudi J Med. 2016; $1(3): 57-62$. 
11. Bakris GL, Molitch M. Microalbuminuria as a risk predictor in diabetes: The Continuing Saga. Diabetes Care. 2014; 37:867-75.

12. Ansar MM, Shahrokhirad R, Lebady MK. Risk factors of microalbuminuria and macroalbuminuria in type 2 diabetic patients in North of Iran - Rasht. Nephrourol Mon. 2017; 9(1):1-5.

13. Kumar KP, Trimalsina S, Sanat C, Anita Y, AK B. Prevalence of microalbuminuria and its association with glycemic control in type 2 diabetic patients: A cross sectional study at Kathmandu Medical College. JCMC. 2019; 9(1):2-7.

14. Showail AA, Ghoraba M. The association between glycemic control and microalbuminuria in type 2 diabetes. Saudi J Kidney Dis Transpl. 2016; $27(3)$ :4739.

15. Efundem NT, Assob JCN, Feteh VF, Choukem SP. Prevalence and associations of microalbuminuria in proteinuria - negative patients with type 2 diabetes in two regional hospitals in Cameroon: A cross sectional study. BMC Res Notes. 2017; 10:6-10.

16. Chen W, Hung C, Wen Y, Ning H, Huang Y. Effect of glycemic control on microalbuminuria development among type 2 diabetes with high- normal albuminuria. Ren Fail. 2014; 36(2):171-5.
17. Khalid A, Samia B, Muneera A, Patan K, Bandari A. Frequency of Microalbuminuria in Saudi Adults with Type 2 Diabetes Mellitus. EC Endocrinol Metab Res. 2018; 3(1):21-9.

18. Memon MY, Mughal MA, Memon SH, Rahu AA. Correlation of Microalbuminuria with Glycated Hemoglobin, Blood Pressure and Duration of Diabetes. J Diabetes Res Endocrinol. 2017; 1(1):1-7.

19. Habib MB, Akbar NS. Association of Microalbuminuria with HbA1c in patients of type II diabetes mellitus in different age groups and genders. Diabetes Case Rep. 2018; 3(3):8-11.

20. Verma MK, Kumar P, Sharma P, Singh VK, Singh SP. Study of microalbuminuria as early risk marker of nephropathy in type 2 diabetic subjects. Int $\mathrm{J}$ Res Med Sci. 2017; 5(7):3161-6.

21. Afifa K, Asma SB, Nabil H, Ahlem B, Mounira S, Kawthar $Y$, et al. Screening for nephropathy in diabetes mellitus: Is Micral-Test Valid among all diabetics? Int J Chronic Disease. 2016; 1-6.

22. Jung D, Byun $Y$, Kwon $Y$, Kim G. Microalbuminuria as a simple predictor of incident diabetes over 8 years in the Korean Genome and Epidemiology Study (KoGES ). Sci Rep. 2017; 7:1-7.

AUTHORSHIP AND CONTRIBUTION DECLARATION
\begin{tabular}{|c|l|l|}
\hline Sr. \# & \multicolumn{1}{|c|}{ Author(s) Full Name } & \multicolumn{1}{c}{ Contribution to the paper } \\
\hline 1 & Shahzad Ali Jiskani & Corresponding author \\
2 & Dolat Singh & Author \\
3 & Kumayl Abbas Meghji & Author \\
4 & Rizwan Ali Talpur & Author \\
5 & Jahanzaib Khan & Author \\
6 & Hina Nazeer Khanzada & Author \\
\hline
\end{tabular}

